\title{
Pig Slaughtering Traceability System Based on RFID and ZigBee Technology
}

\author{
Wusheng Ji \\ Institute of Antenna and Microwave Techniques, \\ Tianjin University of Technology and Education \\ Tianjin, China \\ wshji1326@sohu.com
}

Hong Guo

School of Computer and Communication, Lanzhou University of Technology

Lanzhou, China

527846733@qq.com

\author{
Fengchen Zhang \\ School of Computer and Communication, \\ Lanzhou University of Technology \\ Lanzhou, China \\ 981392689@qq.com
}

\begin{abstract}
In order to improve the management of information slaughterhouse and automation, ensure the safety of pork production, design the wireless RFID reader devices system based on $\mathrm{CC2530}$ by integrating the radio frequency identification technology and the ZigBee network which is used in pig slaughter traceability information. Use CC2530 and MF RC522 to build a wireless RFID reader, build slaughter traceability system software on the Visual Studio 2008 platform. System integration tests showed that the use of ZigBee wireless transmission technology can transmit data with two-way so that the reader system applications more flexible. The system of pig slaughter traceability has high stability of the system, identify the long distance, scalable and improve the pig slaughtering traceability management efficiency. At the same time, the traceability system has a certain reference value applications in the study of domestic food safety issues. It's useful for improving the level of China's food industry information.
\end{abstract}

Keywords-Traceable system; ZigBee; RFID reader; CC2530; MF RC522

\section{INTRODUCTION}

In recent years, the production of livestock appears steady and healthy development However, during the process of pork production, not-standardized corporate governance and product safety issues trigger animal food safety incidents occurs[1]. Therefore, building a perfect traceability monitoring platform is useful to guarantee food security, improve the economy and living standards. Currently, the food traceability generally use RFID radio frequency electronic identification. Since the existing RFID reader is generally based on the cable transmission, there are disadvantages of fixed position reader, poor flexibility, short-distance transmission and high equipment costs. Comparing with cable transmission system, using zigbee wireless transmission technology can achieve two-way wireless data transmission, the reader system applications are more flexible.

At present, China's animal product traceability system based on the theory and practice made significant progress and breakthroughs, and applied to product traceability. Wang PeiQiang, etc. analyze and design pork traceability management system based on RFID and bar code technology[2], and develop a workable traceability coding rules, associated with the entire logistics chain. But there is no detailed study and design for hardware systems product traceability and traceability information collected information. Bao Xiao Cheng, etc. theoretically analyze traceability of pork products, key factors and traceability information systembut[3], but did not realize the system and applied to actual production traceability process.

In this article, we design a portable wireless RFID reader by intergerating ZigBee wireless communication technology and RFID technology. This will make up for the shortcomings of traditional RFID, and it's useful to improve real-time monitoring and network slaughterhouse with the use of ZigBee wireless network technology. Based on C/S we develop traceability system application software on the Visual Studio 2008 platform, and record information of pig slaughter, quarantine and split into the segmentation database center through a wireless RFID reader to achieve production information management; Meanwhile, information inquiry terminal provides information services for enterprise manageent, and managers can query the corporate information, employee information and product information through the terminal.

\section{SYSTEM ARCHITECTURE}

\section{A. System Design}

Slaughter traceability system consists of a wireless RFID reader, ZigBee wireless sensor networks and C / S application software developed on the Visual Studio 2008 development platform. Based on the production process of meat processing factory in Lanzhou, consider HACCP system as theoretical basis [4], combining with the actual production process, to determine the function of the system. With this traceability system record the information of production process into the database, achieve inqury and management of the enterprise and 
employee-related and maintenance of the system-related information.Fig.1 . shows the system architecture.

\begin{tabular}{|c|c|c|}
\hline \multicolumn{3}{|c|}{ Pig slaughter traceability system } \\
\hline $\begin{array}{c}\text { System informati } \\
\text { Maintenance }\end{array}$ & $\begin{array}{l}\text { ine info } \\
\text { record }\end{array}$ & \\
\hline $\begin{array}{l}\text { 1, User information } \\
\text { maintenance }\end{array}$ & $\begin{array}{l}\text { 1, pigs entering the slaughter } \\
\text { plant information }\end{array}$ & 1, information inquiry \\
\hline 2, Farming enterprise & \begin{tabular}{|l} 
2, Ante-mortem information \\
record
\end{tabular} & $\begin{array}{l}\text { 2, farms transfer information } \\
\text { inquiry }\end{array}$ \\
\hline & $\begin{array}{l}\text { 3, Ear tag turn into carcass } \\
\text { tag information input }\end{array}$ & $\begin{array}{l}\text { 3, Quarantine Information input } \\
\text { before Ante-mortem }\end{array}$ \\
\hline information maintance & \begin{tabular}{|l|}
$\begin{array}{l}\text { 4, Pork quarantine information } \\
\text { input }\end{array}$ \\
\end{tabular} & $\begin{array}{l}\text { 4, Quarantine Information input } \\
\text { after Ante-mortem }\end{array}$ \\
\hline $\begin{array}{l}\text { 4, Logistics enterprise } \\
\text { information maintenance }\end{array}$ & $\begin{array}{l}\text { 5, Carcass into the refrigerator } \\
\text { information input }\end{array}$ & $\begin{array}{l}\text { 5, Cold storage information } \\
\text { inquiry }\end{array}$ \\
\hline $\begin{array}{l}\text { 5, Maintenance of user } \\
\text { rights }\end{array}$ & $\begin{array}{l}\text { 6, Carcass turn out information } \\
\text { input }\end{array}$ & 6, Transfer information inquiry \\
\hline
\end{tabular}

Figure 1. Slaughterhouser traceability system structure

\section{B. Main system flow chart}

Throughout the system, ZigBee coordinator form entire ZigBee communication network, waiting for routers and end nodes to join it. During slaughter surveillance process wireless RFID reader collects related node information, and then send it to the first bit machine through ZigBee network, and finally store related information into the database. The main system flow chart is shown in Fig. 2.
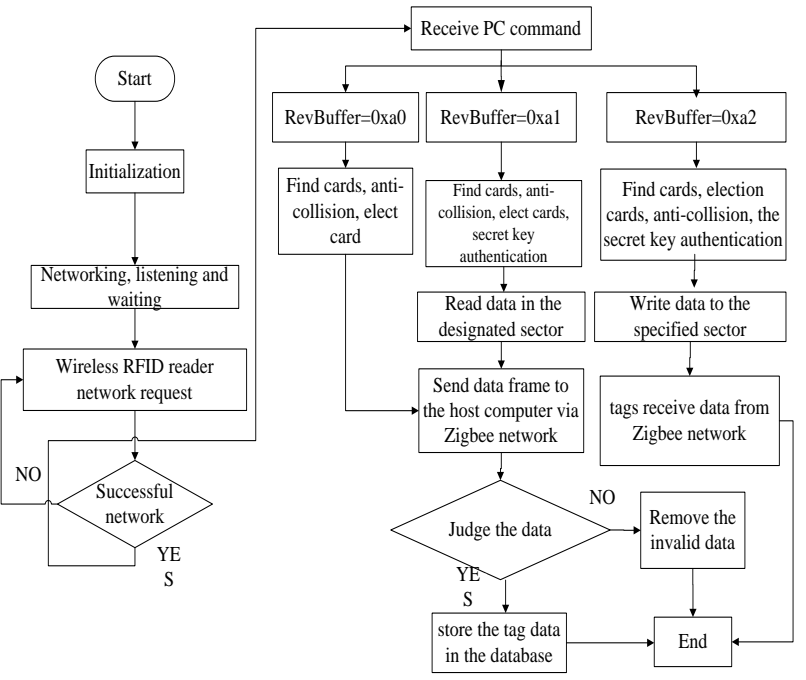

Figure 2. System main program flow chart

In wireless RFID reader, RF chip MF RC522 communicate with electronic tags following the communication protocol of ISO/IEC14443A . Through SPI(Serial Peripharal Interface), CC2530 controls communication between MF RC522 and type matched cards within the range of the antenna, and reads information in card, dealts with the information accordingly to make it compliant with the ZigBee protocol packets[5-6], and then sends the packets to the coordinator in ZigBee network following IEEE 802.15.4[7-10]. Coordinator connectes with the host computer via the UART interface, and ultimately send the data to PC for processing. Similarly, the host computer can send control commands to cooperate the electronic label, such as modification of the information.

\section{DESIGN OF WIRELESS RFID READER}

The main function of mobile RFID reader is information collection, transmission and modification of slaughterhouse traceability. Hardware design of Wireless RFID reader system is about to design RF communication module circuit and ZigBee terminal node and ZigBee coordinator circuit

\section{A. Design of RF Communication Circuit}

$\mathrm{RF}$ function consists of the microprocessor and RF chips, its main function is to communicate with the electronic tag for completing the exchange of the tag information [11]. The core chip of RF module is Philips MF RC522, electronic tags is M1 card produced by Philips. Fig. 3 shows RF communication module circuit.

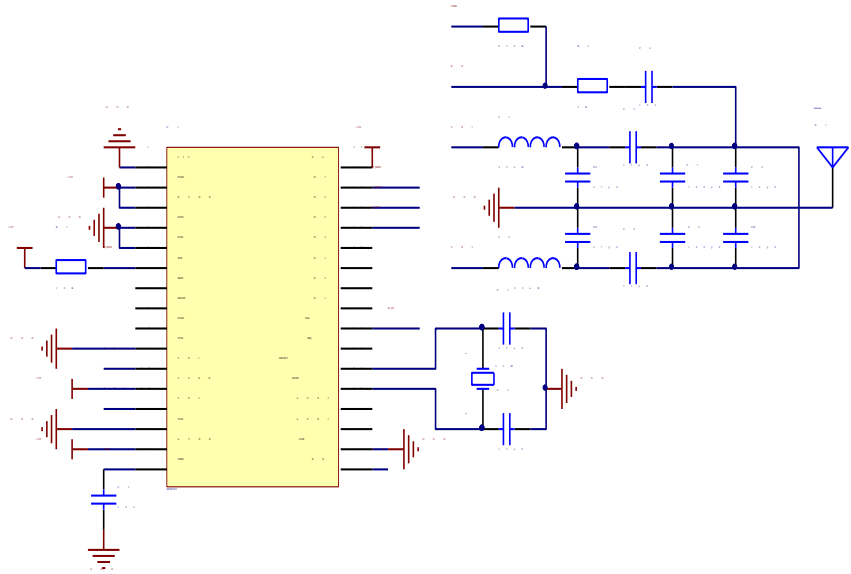

Figure 3. RFID read-write system radio frequency communication module

Fig.3 shows that RF power module $13.56 \mathrm{MHz}$ carrier signal modulated envelope signal sends to antenna module via pin TX1 and TX2. EMC filter circuit consisted of L1, L2, $\mathrm{C} 11$ and $\mathrm{C} 12$, with $\mathrm{C} 5-\mathrm{C} 10$ component drive the antenna, and then send out the signal. In the receiving end, stabilize the DC input voltage of RX pin stabilize through $\mathrm{C} 3$ and $\mathrm{R} 2$, and adjust the AC input voltage through $\mathrm{C} 3$ and $\mathrm{C} 4$

\section{B. Wireless ZigBee module circuit design}

The main function of ZigBee module is to send and receive data. The system uses a CC2530 With low power consumption produced by TI/Chipcon, It integrates IEEE 802.15.4/ZigBee RF transceiver and industry-standard enhanced $8051 \mathrm{MCU}$ kernel, the kernel control circuit is shown in Fig. 4. 


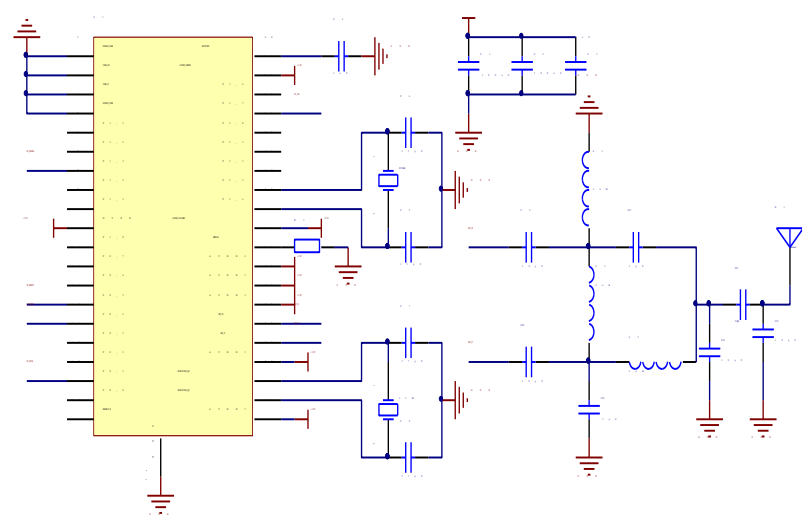

Figure 4. ZigBee core control circuit design

\section{Hardware interface circuit of CC2530 and MF RC522}

The system uses $32 \mathrm{MHz}$ crystal oscillator as a clock signal of CC2530 core controller, CC2530 communicates with RF module through SPI, P1_7 picks SDA end in RF chip MF RC522 as a signal control line. P0_1, P1_3 and P0_4 respectively pick D5, D6 and D7 end in MF RC522, control MF522 related registers write and read through SPI. P0_5 pick Reset pin of MF RC522 for the controller reset. Fig. 5 shows I/O interface connection of CC2530 and MF RC522.

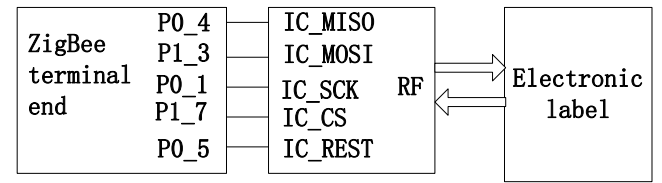

Figure 5. The I/O port connection CC2530 with MF RC522

\section{RFID reader application software design}

In VS2008 development platform, we develop a PC reader software based on serial communication, and use the application software to read electronic label and specified block data, and midify specified block data.The $\mathrm{PC}$ reader application software is shown in Fig. 6.

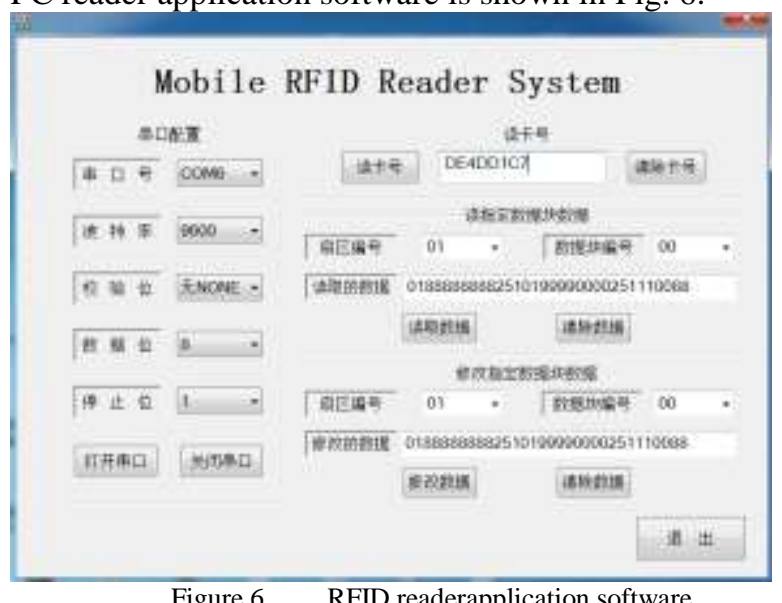

The process that user determine to modify data block 00 in sector 01 explain process of PC writing card. In specified data block, select data block in sector 01 . Write data in the application software interface "modified data" column "01888888882510199990000251110088", click on "Edit Data" button, the data is encoded as "19A2FFFFFFFFFFFF0401888888882510199990000251 110088 ". Account for one byte of every two numbers, where "19" represents 25 bytes sending to the reader, "A2" indicates the data write instruction to be executed, "FFFFFFFFFFFF" is the initial cryptographic data block, "04" represents the fourth block of data block, PC software encodes the control command string for sending data into a binary format, the serial port is sent to the ZigBee coordinator through the PC, and then sent to the ZigBee coordinator through the terminal nodes, terminal nodes control MF RC522 store the data in electronic tag into the corresponding data block. In order to verify whether the data is correct or not, we can read the data in the specified block where just write into it. As Fig. 6 shows, select sector number, data block number ,click "read data", "data read" box can show the data just written.

\section{E. The test results of Wireless RFID reader system}

In order to verify the stability and accuracy of the system, both indoors and outdoors to test the system. Indoor test is to detect the reader transmission distance through the wall, and outdoor is used to detect the reader transmission distance with no obstacle in open area . At temperature $28{ }^{\circ} \mathrm{C}$ and Zigbee nodes transmit power is $4.5 \mathrm{dbm}$, the use of electronic tag reader system for reading and writing tests. The test results are shown in Table I, from the test results, the data transfer distance for system is $80 \mathrm{~m}-100 \mathrm{~m}$ in outdoor, the transmit distance through walls is $30 \mathrm{~m}-50 \mathrm{~m}$, effectively improve the recognition distance of the reader.

TABIE I. THE TEST RESULTS OF WIRELESS RFID READER SYSTEM

\begin{tabular}{cccccc}
\hline $\begin{array}{c}\text { Test } \\
\text { numb } \\
\text { er }\end{array}$ & $\begin{array}{c}\text { Test } \\
\text { environm } \\
\text { ent }\end{array}$ & $\begin{array}{c}\text { Test } \\
\text { distan } \\
\text { ce }\end{array}$ & $\begin{array}{c}\text { Test } \\
\text { frequenc } \\
\text { y(read, } \\
\text { write) }\end{array}$ & $\begin{array}{c}\text { Receive } \\
\text { frequen } \\
\text { cy(read, } \\
\text { write) }\end{array}$ & $\begin{array}{c}\text { Packet } \\
\text { loss rate }\end{array}$ \\
\hline 1 & Indoor & $30 \mathrm{~m}$ & $50 、 50$ & $50 、 50$ & 0 \\
2 & Indoor & $40 \mathrm{~m}$ & $50 、 50$ & $49 、 50$ & $1 \%$ \\
3 & Indoor & $50 \mathrm{~m}$ & $50 、 50$ & $48 、 49$ & $3 \%$ \\
4 & Indoor & $55 \mathrm{~m}$ & $50 、 50$ & $45 、 43$ & $12 \%$ \\
5 & outdoor & $80 \mathrm{~m}$ & $50 、 50$ & $50 、 50$ & 0 \\
6 & outdoor & $90 \mathrm{~m}$ & $50 、 50$ & $50 、 49$ & $1 \%$ \\
7 & outdoor & $100 \mathrm{~m}$ & $50 、 50$ & $49 、 48$ & $3 \%$ \\
8 & outdoor & $105 \mathrm{~m}$ & $50 、 50$ & $44 、 43$ & $13 \%$ \\
\hline
\end{tabular}

\section{SYSTEMS NETWORK COMMUNICATION STRUCTURE}

The existing RFID reader systems are generally based on the cable transmission [14-15], by RS232 or Ethernet interface [16-17] to communicate with the host computer. Because of the RFID reader has poor anti-jamming capability, susceptible to environmental factors. In this paper, it establishs a network based on ZigBee wireless RFID reader by integrating radio frequency identification technology and wireless communication technology. The wireless RFID reader can be achieved related information collection and transmission for the slaughterhouse. The communication system is shown in Fig. 7: 


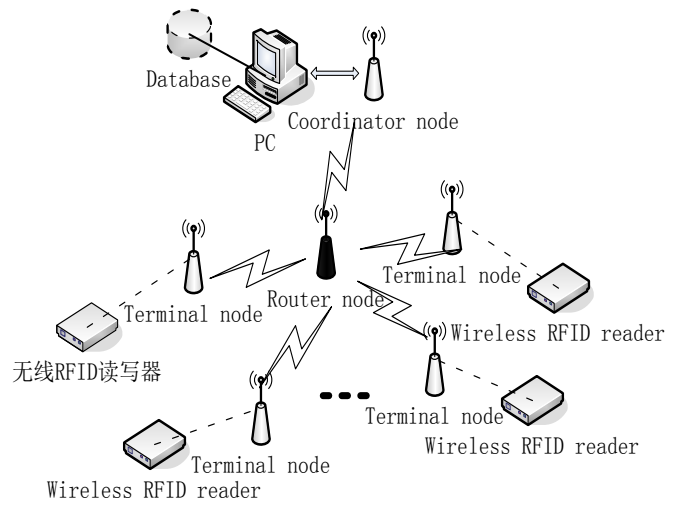

(a) System network communication structure

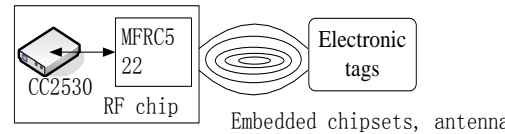

(b) The basic structure of wireless RFID read-write device

Figure 7. System communication structure

Network communication structure of the system is shown in Fig 7 (a), including: (1) wireless RFID reader: collecting the traceability information, then transmitting them to the ZigBee router node by the ZigBee terminal node. At the same time, terminal node According to transmission over the ZigBee router operating instructions to control the RFID reader to the appropriate action. (2) ZigBee router node: responsible for transmitting information. (3) ZigBee coordinator node: responsible for starting the entire ZigBee network, ZigBee router sends the information via the serial port to the host computer system, while the host computer sends control information to ZigBee terminal node. (4) PC: install the application software and achieve human-computer interaction. The basic structure of wireless RFID reader is shown in Fig. 7 (b), including: (1) electronic label: Record label card data and pork products information. (2) reader: consists of the core control chip and CC2530 RF chip. CC2530 RF chip by controlling the electronic tag identification data, and to read and write and other operations related information. Traceability management system is mainly used to pigs slaughter, quarantine, the segmentation, and other real-time information into database center; At the same time, management corporate information, employee information and product information .

ZigBee is based on the IEEE802.15.4 standard low-power personal area network protocol. The ZigBee protocol stack is Z-Stack 2007 by TI, development program in its application layer. To complete the network and product traceability information. The establish network of ZigBee is shown in Fig. 8:

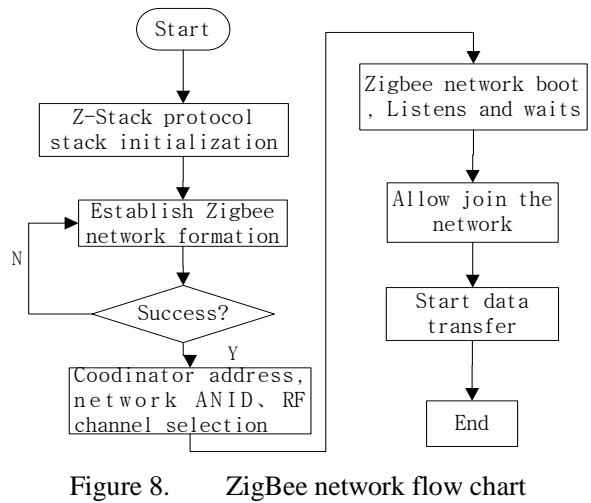

\section{THE DESIGN OF TRACEABILITY MONITORING SYSTEM}

\section{A. The slaughterhouse Information Query System}

Corporate managers can query enterprise information, staff and product information by systems. In the query system, select the check content and the conditions can query to the need information. Information query System module processes is shown in Fig. 9:

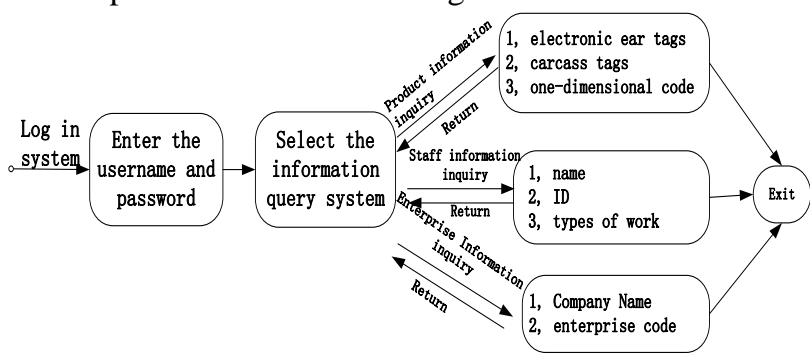

Figure 9. Query module of information system flow chart

B. The quarantine information of slaughterhouse into the system

The relevant information of quarantine is entered into slaughterhouse by the quarantine information module. the quarantine Information module is divided into two parts: quarantine departments and veterinary sectors.To record aspects related indicators are qualified, and recorded the indicators in the central management database. Fig. 10 (a) is a pig carcass visceral the quarantine system modules.Veterinary review the quarantine result for departments and submits audit results to the central database. The the veterinary quarantine system modules is shown in Fig. 10 (b).

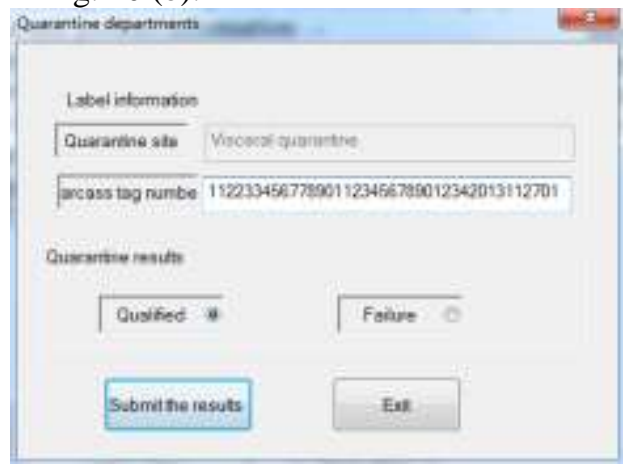

(a) department of quarantine system 


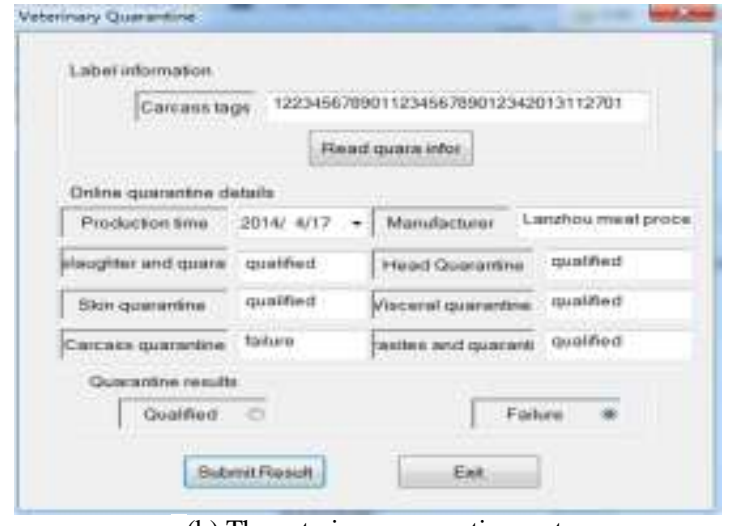

(b) The veterinary quarantine system

Figure 10. Information module of quarantine inspection

\section{The Information Maintenance System of slaughterhouse}

The information maintenance system is mainly divided into three parts: 1 , new employees registered. The new employee's information is recorded into database, and set staff numbers, passwords, access permissions and job sectors. 2, the old employee data updates. When older employees personal information change, using software update records. 3, pigs information management. Use PC software to encode the pigs, and the encoded information is written to the electronic tag, simultaneously recorded into database, the data collection and management system interface is shown in Fig. 11:

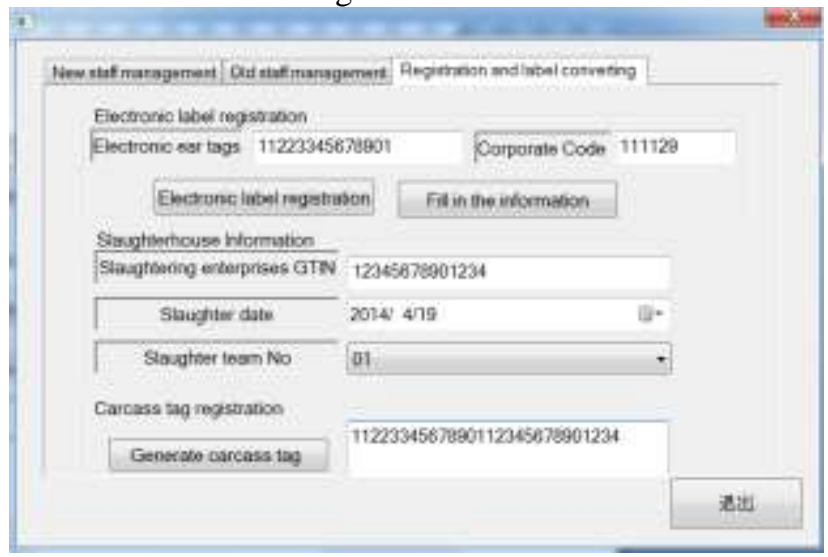

Figure 11. Slaughterhouse data acquisition management system

\section{CONCLUSION}

The safety issue of food has been much attention to people, establish a complete food traceability system is necessary. In this paper, it designs wireless RFID reader and reader applications based on CC2530 by integrating radio frequency identification technology and wireless communication technology. Not only overcome the shortcoings that the RFID reader short distance, poor anti-interference and susceptible to environmental impacts, but also improve the real-time monitoring of slaughterhouses and network. Development and maintenance the quarantine information subsystem, the information input subsystem and information query subsystem, which based on $\mathrm{C} / \mathrm{S}$ structure in the Visual Studio 2008 platform.Meanwhile, adopt the CC2530 chip as micro controller of the reader. so that reduces the cost and power consumption, also eliminates the hassle of wiring. Experiment shows that high stability of the system, long identification distance, application flexibility and extensibility, with the very high economic and practical value.

\section{ACKNOWLEDGMENT}

This work was supported by the City Development Institute of Gansu Prov(2010-GSCFY-KJ07) and the Science and Technology Development Program of Lanzhou (2010-1-226).

\section{REFERENCES}

[1] Cao Z Y, Zhou Y, Li X B, etal. Farm management system design based on traceability technology[J]. Journal of Guangdong Agricultural Science, 2010;37 (6):1-2.

[2] Feng X Z, Wang P Q. Based on RFID and barcode technology of pork traceability management information system analysis and design[D]. Beijing: Software College, Beijing University of Technology, 2012.

[3] Bao X C. Pork food supply chain traceability system based on internet of things researc[J]h. Changsha: Management Science and Engineering College, Changsha University of Science and Technology, $2013: 20-28$.

[4] Qian H, Wang W J. HACCP principle and implemention[M] Beijing: China Light Industry Press, 2003.

[5] Freescale Semiconductor,inc. 2.4 GHz Low Power Transceiver for the IEEE 802.15.4 Standard Reference Manual[EB/OL].2005.8 [2014.3].

http://html.alldatasheet.com/html-pdf/129572/FREESCALE/MC13 192/486/1/MC13192.html.

[6] Texas Instruments .CC2420 2.4GHz IEEE802.15.4/ZigBee-ready RF Transceiver[OL].2013.4 [2014.3] http://www.ti.com.cn/product/cn/cc2420.

[7] Li B, Li W F. WSN can be integrated with the RFID technology research[J]. Computer Engineering, 2008; 34 (9):127-129.

[8] Li W. Based on the ZigBee wireless sensor network communication protocol stack design and implementation[D] Chengdu: College of Automation Engineering, University of Electronic Science and Technology, 2009.

[9] Liu Y, Peng G, WANG T. A method of building network based on ZigBee technology RFID system[J]. Journal of Guangxi Academy of Sciences. 2010; 26 (4) :455-457.

[10] Zhang W C, Yu X W. Based on CC2530 and ZigBee protocol stack design wireless sensor nodes[J]. Computer System Application.2011; 20(7):184-187.

[11] Huang J X, Tao W Q. RFID reader module design based on MFRC522[J]. Micro Computer and Applications, 2010;29 (22):16 $-18$

[12] Jiang T, Zhao C L. Purple wasp technology and its application[M] Beijing: Beijing University of Posts and Telecommunications Publishing House, 2006: 15-19.

[13] Ji W S, Li Y M. RFID pig slaughtering the traceability system research[J]. Computer system application,2012;21 (12):131-132.

[14] Cha S. Research on wireless sensor network gateway based on ZigBee technology and implementation[D]. Dalian: Institute of communication and information, Dalian university of technology, 2007.

[15] Jiang T, Zhao C L. Purple wasp technology and its application[M] Beijing: Beijing University of Posts and Telecommunications Publishing House, 2006:53-100.

[16] Su P, Jiang T, Zhang Y S, etal. RFID read-write device based on the technology of ZigBee network construction[J]. Journal of Guangxi Academy of Sciences,2009;25(4):291-293.

[17] Zhang T, Xiong Z. A bus based RFID research and implementation of interconnected system[J]. Journal of Microelectronics and Computers, 2007; 24 (4):151-155. 